\title{
Control migratorio y derechos fundamentales en la Constitución chilena: algunas consideraciones para el proceso constituyente
}

\author{
Immigration control and Constitutional Rights in the Chilean Constitution: \\ Some considerations for the Constitution-Making Process
}

\author{
Ramón MAYORGA Mc DONALD1
}

Resumen: Pese a no existir en ella referencias explícitas a la inmigración, la doctrina y jurisprudencia constitucionales han considerado que la Constitución de 1980 ha ofrecido a las personas migrantes un alto estándar de protección de sus derechos fundamentales. En el artículo se sostiene que en la futura Constitución es necesario dar continuidad a este marco particularmente garantista, e incorporar normas que dirijan la acción del Estado hacia la adopción de políticas migratorias que se enfoquen en los derechos de las personas migrantes y que favorezcan su integración.

Palabras clave: Derecho constitucional migratorio, Control migratorio, Derechos fundamentales de los migrantes, Proceso constituyente

\begin{abstract}
Despite the absence of explicit references to immigration, constitutional doctrine and case law have considered that the Constitution of 1980 has offered to migrants a rigorous standard of protection of their fundamental rights. This work claims that a future Constitution must preserve this generous constitutional framework, and incorporate norms that direct State towards the adoption of migration policies that focus on the rights and integration of immigrants.
\end{abstract}

\footnotetext{
${ }^{1}$ Profesor del Departamento de Ciencias Jurídicas de la Universidad de Magallanes (Punta Arenas, Chile). Magíster en Derecho y Licenciado en Ciencias Jurídicas y Sociales por la Universidad Austral de Chile. Doctorando en Derecho, mención Constituciona lismo y Derecho de la Universidad Austral de Chile y Doctorando en Derechos Humanos, Democracia y Justicia Internacional de la Universitat de València. Este trabajo fue financiado por la Agencia Nacional de Investigación y Desarrollo (ANID) / Programa de Becas / DOCTORADO NACIONAL / 2019 - 21190529. Correo electrónico: ramon.mayorga@umag.cl
} 
Keywords: Constitutional Immigration Law, Immigration Control, Fundamental Rights of Immigrants, Constituent Process

\section{Introducción}

Las cifras publicadas en marzo de 2020 por el Instituto Nacional de Estadísticas de Chile (INE) en conjunto con el Departamento de Extranjería y Migración del Ministerio del Interior (DEM) arrojaron que al 31 de diciembre de 2019 residían aproximadamente 1,5 millones de extranjeros en el país, cifra que se acerca al $8 \%$ del total de la población ${ }^{2}$. Aquello evidencia que la inmigración se ha transformado en un rasgo estructural de la sociedad chilena contemporánea, cuestión que ha sido erráticamente abordada por el Estado ${ }^{3}$. En este contexto, se encuentra aprobada una nueva Ley de Migración y Extranjería (cuya promulgación espera al momento del envío de este artículo), en reemplazo del Decreto Ley № 1.094 de 1975, vigente por más de cuarenta años.

El referido Decreto Ley había sido profundamente cuestionado no solo por su carácter anacrónico a la luz del actual panorama de la inmigración en Chile, sino que también por su regulación lesiva de derechos fundamentales básicos de las personas migrantes, tales como el derecho a la no discriminación, el derecho a un debido proceso o el derecho a la libertad personal y a la seguridad individual. Además, no existía en él referencia alguna al reconocimiento de derechos como el acceso al sistema de salud, al sistema educativo o a la vivienda, ocupándose exclusivamente de las materias asociadas al control del ingreso y la permanencia de los extranjeros en territorio chileno. Los desafíos jurídicos que involucra el aumento de la inmigración, exigieron a la doctrina nacional y a los operadores jurídicos pronunciarse en torno a si la vigente Constitución de 1980 ofrecía o no una respuesta al modo en que el Estado ha de abordar el diseño y la implementación de sus políticas de control a la inmigración.

El objetivo tras las líneas que siguen es dar cuenta de la incidencia que las normas constitucionales han tenido sobre el Derecho Migratorio chileno, y en especial sobre la protección de los derechos de las personas migrantes sujetas al control de la autoridad migratoria administrativa. Dicha revisión permitirá sostener como hipótesis que la Constitución de 1980 es particularmente garantista en relación con los derechos de las personas extranjeras, excluyendo un tratamiento discriminatorio, arbitrario o restrictivo en el ejercicio de sus

${ }^{2}$ Instituto Nacional de Estadísticas y Departamento de Extranjería y Migración (2020): Informe Estimación de Extranjeros Residentes en Chile al 31 de diciembre de 2019. [Disponible en: https://bit.ly/3qw94Rk].

${ }^{3}$ Stefoni y Brito (2019), pp. 33-41. 
derechos. Puede que esto resulte contra intuitivo, tomando en consideración el contexto especialmente hostil hacia "lo extranjero" en que se gestó esta4. Sin embargo, veremos que por diversas razones la inspiración nacionalista de la dictadura militar acabó cediendo frente a un sistema amplio de libertades, que robusteció el estatuto de protección de las personas extranjeras en el país.

El proceso constituyente, actualmente en curso, demanda evidenciar los rasgos que, bajo el actual marco constitucional, han permitido extender la garantía de los derechos fundamentales de los migrantes ante los tribunales de justicia. Como en cualquier momento constituyente, existe el riesgo de regresividad en materia de derechos de los migrantes, que resulta necesario evitar. Así, este artículo tiene por objeto, además, ofrecer algunas reflexiones sobre la importancia del tratamiento de esta cuestión por la Convención Constitucional. Para todo ello, las páginas que siguen revisan la experiencia comparada, y desarrollan los rasgos más destacables del actual texto constitucional en la materia, a partir de la doctrina y jurisprudencia más relevante.

\section{Constitución y migración: marco constitucional de las políticas de control a la inmigración en el derecho comparado}

No son pocas las constituciones que, a nivel comparado, incorporan disposiciones relacionadas con la migración ya sea desde lo orgánico o desde lo sustantivo. Desde lo orgánico, un número significativo de constituciones contempla disposiciones que confieren competencias en materia migratoria y de extranjería a distintos órganos. Esto ocurre fundamentalmente en algunos Estados con una forma política descentralizada, en los que se hace necesaria una definición competencial entre el nivel central y las sub-unidades territoriales. Es el caso particular de Alemania, Brasil y España. En el caso de la Ley Fundamental Alemana, se incorpora entre las materias que abarca la legislación concurrente, el derecho de residencia y establecimiento de los extranjeros 5 . La Constitución brasileña, del mismo modo, establece que la Unión tiene poder legislativo exclusivo con respecto a emigración, inmigración, entrada, extradición y expulsión de extranjeros ${ }^{6}$. La Constitución española, en tanto, consagra como

\footnotetext{
${ }^{4}$ Desde el mismo 11 de septiembre de 1973, la Junta Militar aplicaría un especial rigor a los "activistas extranjeros", ante el "patriótico compromiso de restauración de la chilenidad" (Decreto Ley № 1). La influencia extranjera había sido considerada por las Fuerzas Armadas una de las causas que precipitó al golpe de Estado, de modo que el régimen tenía una inspiración marcadamente nacionalista. A esto hay que sumar los conflictos que durante la década de 1970 tenía Chile con sus países vecin os. ${ }^{5}$ Ley Fundamental Alemana (1949), artículo 74 inciso 1 no 4 .

${ }^{6}$ Constitución de la República Federativa de Brasil (1988), artículo 22 XV.
} 
competencia exclusiva del Estado las materias relativas a nacionalidad, inmigración, emigración, extranjería y derecho de asilo7.

Pese a que estas disposiciones se pronuncian acerca del órgano competente para regular la cuestión, en general, no entregan pautas explícitas acerca de los rasgos que la legislación migratoria debiese adoptar. Esto sí se produce en un conjunto de textos constitucionales que, desde lo sustantivo, incorporan principios o directivas en materia de políticas migratorias, en un sentido más o menos receptivo con los flujos de movilidad. Un caso emblemático es el de la Constitución ecuatoriana de 2008. Esta refleja una comprensión integral del fenómeno de la movilidad, traducida en la incorporación de un conjunto de artículos referidos a la situación de las personas migrantes, refugiadas y desplazadas. Entre los artículos más destacados, se encuentra aquel que consagra el derecho de las personas a migrar ${ }^{8}$, al asilo y al refugio ${ }^{9}$. De igual modo, la prohibición del desplazamiento arbitrario ${ }^{10}$, el principio de no devolución y la prohibición de expulsiones colectivas ${ }^{11}$.

La Constitución argentina es otra de las cartas fundamentales latinoamericanas que, pese a la larga data de muchas de sus disposiciones, proyectó una política migratoria generosa, aunque concediendo a la autoridad estatal competencia para regular el ingreso y salida de extranjeros ${ }^{12}$. En efecto, ya en su preámbulo es posible interpretar una mirada de los constituyentes argentinos en este sentido, al declararse que se ordena, decreta y establece dicha Constitución asegurando así los beneficios de la libertad no solo para los nacidos en su territorio, sino que también para “(...) todos los hombres del mundo que quieran habitar el suelo argentino"13. Igualmente, se ordena al Gobierno federal fomentar la inmigración europea, sin poder restringir, limitar ni gravar con impuesto alguno la entrada al territorio argentino de los extranjeros que traigan por objeto labrar la tierra, mejorar las industrias e introducir y enseñar las ciencias y las artes ${ }^{14}$.

En una dirección opuesta, la Constitución uruguaya establece que en ningún caso el inmigrante adolecerá de defectos físicos, mentales o morales que puedan perjudicar a la sociedad, no considerando las potenciales ventajas de la inmigración, sino que más bien sus

\footnotetext{
${ }^{7}$ Constitución Española (1978), artículo 149 no 2.

${ }^{8}$ Constitución de la República del Ecuador (2008), artículo 40.

${ }^{9}$ Constitución de la República del Ecuador (2008), artículo 41.

${ }^{10}$ Constitución de la República del Ecuador (2008), artículo 42.

${ }^{11}$ Constitución de la República del Ecuador (2008), artículo 66 no 14.

${ }^{12}$ Arlettaz (2018), pp. 284-286.

${ }^{13}$ Constitución de la Nación Argentina (1994), preámbulo.

${ }^{14}$ Constitución de la Nación Argentina (1994), artículo 25.
} 
consecuencias "indeseables"15. La Constitución panameña, en tanto, mandata al legislador a regular la inmigración atendiendo a los intereses sociales, económicos y demográficos del país ${ }^{16}$.

Existe también un número significativo de textos constitucionales en los que vocablos como "migración” o "inmigrante" están completamente ausentes y que, en principio, guardan completo silencio sobre el asunto. A estos se suman aquellos que, como mencionamos antes, únicamente cuentan con pronunciamientos desde lo orgánico. Un ejemplo de este fenómeno es el caso español. La Constitución de 1978 dedica un precepto específico a los emigrantes españoles, encomendando al Estado a velar por sus derechos en el extranjero y promover su retorno ${ }^{17}$. En cambio, nada dice en relación a la inmigración y a la forma en que el Estado español debe abordarla.

En ninguno de los ordenamientos constitucionales en que sucede esto último, la ausencia de disposiciones explícitas ha significado un obstáculo para que, de todos modos, el resto de las normas constitucionales incidan en la configuración, aplicación e interpretación del derecho migratorio interno. En el caso español, por ejemplo, la entrada en vigencia de la Constitución de 1978 incidió enseguida en el trato a los inmigrantes por parte de la autoridad estatal. El sistema general de libertades y las reglas del Estado Democrático de Derecho influyeron sobre todos los poderes públicos (en especial sobre la Administración, que pasaba a mejorar su actuación, en general, y en el tratamiento de los extranjeros). Además, la nueva democracia procedió enseguida a la aprobación de los principales tratados internacionales de derechos humanos ${ }^{18}$.

Un caso emblemático en lo que respecta a la constitucionalización del derecho migratorio durante la segunda mitad del s. XX, es el resuelto por el Consejo de Estado francés en el fallo arrêt Ministre de l'Intérieur contre Dame Montcho del 11 de julio de 1980. El señor Montcho, extranjero residente de forma regular en Francia desposó a dos mujeres en su país de origen (Dahomey, actual Benín), de conformidad a su legislación nacional que autorizaba la poligamia. La primera esposa e hijos obtuvieron el visado para residir en Francia, más no la segunda esposa e hijos. El argumento de la autoridad migratoria francesa para el rechazo del visado, fue que la unión poligámica era atentatoria del orden público. En consecuencia, se ordenó la expulsión inmediata tanto de la segunda cónyuge, como de sus hijos. El Consejo de Estado resolvió razonando que la existencia del derecho de las familias extranjeras a reconstituirse, de conformidad al preámbulo

\footnotetext{
${ }^{15}$ Constitución de la República Oriental del Uruguay (1967), artículo 37.

${ }^{16}$ Constitución Política de la República de Panamá (1972), artículo 14.

${ }^{17}$ Constitución Española (1978), artículo 42.

${ }^{18}$ Aja (2012), pp. 66-67.
} 
de la Constitución francesa de 1948, era incompatible con la expulsión decretada. En efecto, la segunda esposa del señor Montcho llevaba cinco años en el país y era tutora legal de sus hijos, por lo que la expulsión ocasionaría un grave perjuicio a la unidad familiar ${ }^{19}$.

Este ha sido el modo en que ha operado el proceso de "constitucionalización" del derecho migratorio y de extranjería en el nivel comparado. Por lo general, más que las disposiciones explícitas, han sido las disposiciones generales y de derechos fundamentales las que mayor incidencia han tenido en la aplicación e interpretación de las leyes de inmigración y extranjería en clave constitucional. Aquello ha contribuido a la reconfiguración de las legislaciones estatales encargadas de gestionar los flujos migratorios, en la medida que se han fortalecido las garantías de que gozan los extranjeros en el territorio del Estado receptor. En particular, esta incidencia se ha producido desde aquella dimensión del proceso que Favoreu ha llamado "constitucionalización-transformación". En virtud de esta, los derechos y libertades constitucionales no solo impregnan las diversas ramas del derecho, sino que las transforman, al provocar un cambio en su contenido 20 .

\section{La "constitucionalización" del derecho migratorio y de extranjería por los tribunales en Chile}

A diferencia de varios de los textos constitucionales revisados, y al igual que constituciones como la francesa o la española, no es posible encontrar en el articulado de la Constitución chilena de 1980 expresiones como "movilidad humana", "migración” o "migrante”. Sin perjuicio de esto, y como en cualquier otro texto constitucional, es posible identificar un estatuto sobre nacionalidad y extranjería. Esta omisión puede explicarse fácilmente considerando que, por obvias razones, durante la Dictadura Militar nuestro país no fue un destino atractivo para emprender proyectos migratorios, sino que, por el contrario, fue fuente de una diáspora que huía de la persecución política y los atropellos a los derechos humanos. Es más, durante dicha época de la historia reciente, el país alcanzó el mínimo histórico de población extranjera residente en el país: apenas un 0,7\% del total de la población, en el año $1982^{21}$.

Sin embargo, y tal como señalamos en el apartado anterior, la ausencia de disposiciones expresas no ha sido un impedimento para que las normas constitucionales incidan en el diseño

\footnotetext{
${ }^{19}$ Consejo de Estado francés, arrêt Ministre de l'Intérieur contre Dame Montcho, de 11 de julio de 1980.

${ }^{20}$ Favoreu (2001), pp. 40-41.

${ }^{21}$ Lara (2014), p. 81.
} 
y la implementación de las políticas de control a la inmigración. Han sido los tribunales de justicia quienes han generado esta incidencia, a través de ejercicios propios del fenómeno de “constitucionalización” del ordenamiento jurídico. En el Derecho chileno, el proceso de constitucionalización del derecho ha también impactado en las leyes de inmigración y extranjería, particularmente en materia de derechos fundamentales. Es el caso del impacto que ha tenido la regla de titularidad de los derechos fundamentales consagrados en el artículo 19, el derecho a la igualdad y no discriminación (artículo 19 no 2), el derecho a la libertad de circulación y residencia (artículo 19 no 7 literal a) y el derecho a un debido proceso (artículo 19 no 3 inc. 6).

\subsection{LA TITULARIDAD DE DERECHOS DE LAS PERSONAS EXTRANJERAS EN LA CONSTITUCIÓN DE 1980}

Una pregunta fundamental a la hora de identificar el marco constitucional de la inmigración dice relación con la titularidad de derechos fundamentales de las personas extranjeras. Esta es una cuestión plenamente atingente, en la medida que la titularidad de derechos para los extranjeros en el orden interno históricamente ha seguido un ritmo distinto a la titularidad de derechos para los nacionales. Por lo mismo, no es de extrañar que los extranjeros acaben considerándose “ciudadanos de segundo orden, a los que se 'regatea' el reconocimiento de sus derechos y garantías en condiciones de igualdad con los nacionales"22. Es frecuente el establecimiento de una titularidad diferenciada de derechos para los extranjeros en relación a los nacionales ${ }^{23}$. En muchos casos, las diferenciaciones de estatuto suponen el establecimiento de verdaderos "estados de excepción permanentes" para las personas migrantes, lo que pugnan abiertamente con la pretendida universalidad en el ejercicio de los derechos fundamentales ${ }^{24}$.

En contraste con esta tendencia comparada, la tradición jurídica chilena ha sido generosa en el reconocimiento de derechos a los extranjeros ${ }^{25}$. A diferencia de otros textos constitucionales comparados, en Chile no existe una disposición constitucional que expresamente se pronuncie

\footnotetext{
${ }^{22}$ De Lucas (2016), p. 23.

${ }^{23}$ La Constitución salvadoreña establece, por ejemplo, que los extranjeros estarán sujetos a una ley especial, perdiendo el derecho a residir en el país si participaren directa o indirectamente en la política interna. Constitución de la República de El Salvador (1983), artículo 100. La Constitución Política de la República de Honduras es un caso particularmente restrictivo de titularidad de derechos a los ciudadanos extranjeros. Establece, por ejemplo, que, en igualdad de condiciones, los trabajadores hondureños tendrán preferencia sobre los trabajadores extranjeros (artículo 137).

${ }^{24}$ De Lucas (2011), p. 4; De Lucas (2016), p. 95.

25 "La tradición constitucional chilena tiene un peso normativo por sí mismo (...) Esta tradición dispone respecto de los extranjeros cuatro elementos señeros que configuran sus tendencias permanentes: (i) asilo al extranjero contra la opresión (ii) reconocim iento de titularidades genéricas, sin distinción de nacionalidad, para algunos o todos los derechos asegurados constitu cionalmente; (iii) permisión y regulación temprana de la posibilidad de que extranjeros obtengan la nacionalidad chilena, cumpliendo ciertos requisitos de residencia y subsistencia; (iv) establecimiento de reglas de trato que en ningún texto constitucional implicasen una regulación hostil al extranjero". Tribunal Constitucional, Rol № 4757-18-CDS, de 19 de julio de 2018.
} 
acerca de la titularidad de derechos fundamentales de los extranjeros. Sí existe, en cambio, una disposición de carácter general: el encabezado del artículo 19. Dicha disposición establece: "la Constitución asegura a todas las personas", para dar luego paso a veintiséis numerales que consagran un catálogo de derechos fundamentales.

La incorporación del vocablo "personas" para designar a los titulares de derechos fundamentales por parte de la Constitución de 1980 es una innovación dentro de la historia constitucional chilena. Ya el Código Civil de 1857 estableció que "la ley no reconoce diferencias entre el chileno y el extranjero en cuanto a la adquisición y goce de los derechos civiles que regla este Código" 26 , tratándose de la primera codificación civil que estableció el principio de igualdad entre nacionales y extranjeros en relación a la adquisición y goce de los derechos civiles ${ }^{27}$. Sin embargo, la Constitución de 1833 y la de 1925 extendieron la titularidad de derechos a "todos los habitantes de la República"28 y a "los habitantes de la Nación”29, respectivamente. En este sentido, la Constitución de 1980 incorporó una regla de titularidad más amplia, desechando el criterio de la habitación como diferenciador para la atribución de derechos fundamentales ${ }^{30}$.

Existe un amplio consenso en la dogmática constitucional en relación a que esta disposición no distingue entre nacionales y extranjeros, haciendo extensiva a estos últimos la titularidad de todos los derechos fundamentales allí consagrados ${ }^{31}$. No obstante, respecto a los derechos políticos, la regla general es que están reservados para los chilenos, en la medida que la ciudadanía se encuentra siempre asociada a la nacionalidad ${ }^{32}$. Este es el motivo por el cual algunos autores han planteado que en el derecho constitucional chileno existen, pese a la regla del artículo 19, algunos derechos asegurados exclusivamente para los nacionales ${ }^{33}$. Sin embargo, aún teniendo esto presente, la Constitución chilena sigue siendo un caso paradigmático de concesión amplia del derecho a sufragio a los extranjeros avecindados en Chile por más de cinco años ${ }^{34}$.

\footnotetext{
${ }^{26}$ Código Civil (1857), artículo 57.

${ }^{27}$ Alessandri, Somarriva y Vodanovic (2007); Tapia (2005).

${ }^{28}$ Constitución Política de la República de Chile (1833), artículo 12.

${ }^{29}$ Constitución Política de la República de Chile (1925), artículo 10.

${ }^{30}$ Contreras (2017), p. 131.

${ }^{31}$ Cea (2012), p. 51 y Aldunate (2008), p. 152.

32 Constitución Política de la República de Chile (1980) artículo 13: "Son ciudadanos los chilenos que hayan cumplido dieciocho años de edad y que no hayan sido condenados a pena aflictiva. La calidad de ciudadano otorga los derechos de sufragio, de opt ar a cargos de elección popular y los demás que la Constitución o la ley confieran (...)”.

33 Zúñiga (1998), pp. 306-307.

${ }^{34}$ Constitución Política de la República de Chile (1980) artículo 14.
} 
La consecuencia evidente de esta amplia titularidad, dice relación con que las personas extranjeras en contexto de movilidad gozan de idénticos derechos a los nacionales, salvo en aquellos casos excepcionales previstos por la propia Constitución. Para la doctrina constitucional chilena ha sido fuertemente llamativa "la falta de diferenciación (entre nacionales y extranjeros), que sí se encuentra presente en la mayor parte de los sistemas constitucionales"35. En el mismo sentido, se ha sostenido que "es una paradoja que el estatus constitucional garantista concede o reconozca a extranjeros un plus de derechos constitucionales, comparado con el estándar mínimo internacional”36, esto considerando que en varios sentidos la protección constitucional puede llegar a superar a la internacional.

Esta regla de titularidad amplia es producto de que la inspiración nacionalista de la dictadura haya cedido ante la filosofía política liberal que subyace a la Constitución de 1980, donde prima el individualismo exagerado y libre de interferencias, tendiendo hacia la minimización de la acción estatal. En dicho acomodo, la configuración amplia de las libertades individuales persiguió instalar un modelo de Estado que garantice la protección de la propiedad privada y la libre iniciativa particular ${ }^{37}$, incluyendo la inversión extranjera.

Esta cuestión estuvo presente en la discusión que giró en torno a la regla de titularidad de los derechos consagrados en el catálogo del artículo 19 del texto constitucional. Allí se planteó, por ejemplo, que la ampliación de dicha titularidad a todas las "personas" solo traía como ventaja un pronunciamiento más inequívoco en orden al reconocimiento y garantía de los derechos patrimoniales de extranjeros no residentes en el país. Es decir, originalmente no existió una especial consideración por ampliar la titularidad de derechos a los migrantes. Más bien se pensó en los inversionistas extranjeros. En este sentido fue expresado por el comisionado Enrique Evans durante una de las sesiones de la Comisión Ortúzar:

(...) La única ventaja (...) de esto de decir "personas" en vez de habitantes, es impedir que, el día de mañana, se estime que el derecho de propiedad sólo ampara a quienes residen en Chile, y en consecuencia, si hay extranjeros no residentes, no habitantes, que tienen propiedades de cualquier especie en este país, a ellos les pudiera afectar otra normativa que fuera ésta de la garantía constitucional del derecho de propiedad, o que se pudiera conculcar o expropiar en otra forma, confiscar, expoliar, para ser más amplio y más genérico, sus propiedades al margen de la garantía constitucional ${ }^{38}$.

\footnotetext{
${ }^{35}$ Aldunate (2008), pp. 192-193.

${ }^{36}$ Zúñiga (1998), p. 329.

${ }^{37}$ Fermandois (2006), pp. 73-74.

${ }^{38}$ Actas de la Comisión Ortúzar, Sesión 156o del 7 de octubre de 1975.
} 


\subsection{EL DERECHO A LA IGUALDAD Y NO DISCRIMINACIÓN (ARTÍCULO 19 № 2)}

Este derecho, consagrado en el numeral segundo del artículo 19 de la Constitución, es una de las garantías más relevantes para un extranjero residente en cualquier país ${ }^{39}$. Su elemento central es la inadmisibilidad de cualquier discriminación arbitraria, pese a que no sea posible encontrar dicha expresión explícitamente en el texto del artículo 19 no 2 . No obstante, se ha señalado que la expresión "discriminar" aparece implícita en esta disposición, al prohibirse a la ley y a autoridad alguna establecer diferencias arbitrarias ${ }^{40}$. En la doctrina y jurisprudencia constitucional chilena, se ha entendido por discriminación arbitraria toda diferencia realizada sin justificación racional o razonable ${ }^{41}$.

Sin duda, la población migrante es un colectivo susceptible de ser víctima de discriminaciones arbitrarias por parte de órganos estatales o de particulares. En efecto, además de constituir una "minoría"42, suele caracterizársele como un "grupo desaventajado" 43 al interior de la sociedad. Esto es así, en la medida que existen a su respecto una serie de estereotipos que fundan prácticas discriminatorias en su contra. En Chile, por ejemplo, esta situación se agrava en relación a los migrantes afrodescendientes, acrecentando la xenofobia y el racismo contra ciudadanos colombianos, dominicanos y haitianos ${ }^{44}$.

Aunque la nacionalidad es una de las principales categorías por las cuales se discrimina a las personas migrantes, esto también sucede en atención a su sexo, raza, idioma o religión. En Chile, la discriminación racial no es un fenómeno nuevo. Ya en el año 1993, la Corte de Apelaciones de Santiago conocía de una acción interpuesta por una persona de nacionalidad coreana impedida de atenderse en un local que brindaba servicio al público de baños turcos y de cajón en temporada invernal, debido al "desagradable hedor" que emanaba de su cuerpo, atribuible a sus costumbres alimenticias ${ }^{45}$.

\footnotetext{
39 Constitución Política de la República de Chile (1980), artículo 19 no 2: “La Constitución asegura a todas las personas: 2o- La igualdad ante la ley. En Chile no hay persona ni grupo privilegiados. En Chile no hay esclavos y el que pise su territorio queda libre. Hombres y mujeres son iguales ante la ley. Ni la ley ni autoridad alguna podrán establecer diferencias arbitrarias (...)".

${ }^{40}$ Díaz (2013), p. 639.

${ }^{41}$ Evans de la Cuadra (1999), p. 125 y Díaz (2013), p. 640. En el mismo sentido, el Tribunal Constitucional, por ejemplo, en: Rol № 1204-08-INA, de 28 de julio de 2009, considerando 13우; Rol № 811-2007, de 31 de enero de 2008, considerando 13ㅇ․

${ }^{42}$ Atendiendo a un elemento fundamentalmente "aritmético", la expresión "minorías" alude a aquellos colectivos numéricamente inferiores al interior de la sociedad. Montilla (1999), p. 119.

${ }^{43}$ La expresión "grupo desaventajado" atiende, en cambio, a un elemento sociológico y no meramente aritmético. Fiss (1999), pp. 138-144.

${ }_{44}$ Tijoux (2018), p. 49.

${ }^{45}$ Corte de Apelaciones de Santiago, Rol № 486-93, de 7 de abril de 1993.
} 
Sin embargo, ha sido en la última década donde la jurisprudencia constitucional ha desarrollado con mayor fuerza la condición de grupo desaventajado de la población migrante, en el contexto de apogeo de nuevos flujos migratorios hacia Chile. A la luz del derecho a la igualdad y no discriminación, se han aportado valiosos insumos en relación a la incidencia de este derecho fundamental en el tratamiento estatal de la inmigración. El punto de partida ha sido precisar que, tal como abordamos en el apartado anterior, la Constitución chilena "no solo no discrimina contra los extranjeros, sino que les reconoce tal título de derechos plenamente" 46 , lo que "no autoriza una titularidad diferenciada de derechos para el extranjero, salvo expresa autorización constitucional”"47. En este sentido, el Tribunal Constitucional ha sostenido que:

(...) la distinción 'extranjero - chileno' puede realizarse y el texto fundamental no la prohíbe. Sin embargo, se trata de una distinción que es sospechosa, en línea de principio, puesto que requiere de una habilitación constitucional previa para poder realizarla. (...) Ello exige una fuerte argumentación contraria que demuestre la necesidad, justificación y finalidad en un objetivo constitucionalmente legítimo que apodere a la Administración del Estado a realizar una diferencia de trato entre ellos ${ }^{48}$.

Efectivamente, la jurisprudencia constitucional ha planteado que distinguir entre "chilenos" y "extranjeros" exige una habilitación constitucional expresa cuando se persiga la privación de un derecho. Este presupuesto concurre, por ejemplo, cuando a propósito de la libertad de trabajo, la Constitución tolera la discriminación en atención a la nacionalidad del trabajador para el desempeño de determinadas ocupaciones, mientras que en otras circunstancias aquella distinción podría calificarse de inconstitucional ${ }^{49}$. Distinto es el caso en que la distinción "nacional - extranjero" se realice con el fin de limitar el ejercicio de un derecho50. Aquí el Tribunal Constitucional ha planteado que no resultan exigibles habilitaciones constitucionales previas, en la medida que:

(...) las limitaciones se fundan en la Constitución y, normalmente, en apoderamientos al legislador bajo las reglas propias de la reserva legal y con las restricciones jurídicas que nacen del principio de proporcionalidad y del respeto al contenido esencial de los derechos ${ }^{51}$.

\footnotetext{
46 Tribunal Constitucional, Rol № 2273-2012-INA, de 4 de julio de 2013, considerando 29․

47 Tribunal Constitucional, Rol № 2273-2012-INA, de 4 de julio de 2013, considerando 29ㅇ․

48 Tribunal Constitucional, Rol № 2273-2012-INA, de 4 de julio de 2013, considerando 30 ․

49 "Se prohíbe cualquiera discriminación que no se base en la capacidad o idoneidad personal, sin perjuicio de que la ley pueda exigir la nacionalidad chilena o límites de edad para determinados casos". Constitución Política de la República, 1980, artículo 19 no 16 inciso tercero.

${ }^{50}$ En tal sentido, por ejemplo, se ha declarado constitucional el establecimiento de la expulsión como una medida alternativa al cumplimiento de ciertas penas para extranjeros sin residencia legal en Chile. Esto, toda vez que dicha medida no supondría la privación de un derecho, sino una limitación respecto de la cual se encontrarían debidamente resguardados los derechos fundamentales del afectado. Tribunal Constitucional, Rol № 2230-2012-CPR, de 5 de junio de 2012.

51 Tribunal Constitucional, Rol № 2273-2012-INA, de 4 de julio de 2013, considerando 30ㅇ․
} 
En consecuencia, el reconocimiento del derecho a la igualdad ante la ley, y a la no discriminación en los términos amplios de la Constitución chilena, supone una potente protección para las personas migrantes en Chile. En la medida que un tratamiento diferenciado entre "nacionales" y "extranjeros" es admitido excepcionalmente, la regla general es el sometimiento a un idéntico estatuto jurídico. De allí que la configuración de un sistema de control migratorio respetuoso de este derecho excluya un trato discriminatorio para las personas migrantes, en relación a los nacionales, y también entre extranjeros, atendiendo a cualquiera de las categorías sospechosas reconocidas. Esto último es relevante, en la medida que es frecuente que el ingreso o la permanencia de personas extranjeras en un país distinto al de su nacionalidad, se supedite a requisitos como la condición socio económica ${ }^{52}$.

\subsection{EL DERECHO A UN DEBIDO PROCESO (ARTÍ́CULO 19 № 3 INC. 6)}

La condición desaventajada de las personas migrantes repercute en su relacionamiento con los órganos estatales. Por lo general, las personas migrantes desconocen el funcionamiento de las instituciones y los derechos que tienen frente a las mismas. A veces tampoco dominan el idioma oficial. De allí que resulte esencial que las decisiones tomadas por los órganos estatales en relación a sus derechos sean producto de un debido proceso, que les asegure ciertas garantías mínimas, al igual que a los nacionales. Aunque no exista en la Constitución de 1980 disposición alguna que consagre un derecho al debido proceso en términos explícitos, se ha sostenido que este se encuentra en el artículo 19 no 3 inciso sexto, el cual reconoce una serie de derechos procesales específicos ${ }^{53}$. El Tribunal Constitucional, en tanto, ha señalado que:

(...) entre los elementos fundamentales del debido proceso se encuentran, entre otros, el conocimiento oportuno de la acción, la posibilidad de una adecuada defensa y la aportación de pruebas, así como el derecho a impugnar lo resuelto a través de un tribunal ${ }^{54}$.

No obstante, dentro del referido artículo 19 n 3, ha destacado el inciso sexto, el cual establece que: “Toda sentencia de un órgano que ejerza jurisdicción debe fundarse en un proceso previo

\footnotetext{
${ }^{52}$ En el Decreto Ley № 1.094, por ejemplo, se prohíbe el ingreso al país a "los que no tengan o no puedan ejercer profesión u oficio, o carezcan de recursos que les permitan vivir en Chile sin constituir carga social” (artículo 15 no 4), cuestionándose si esta causal cumple o no con el principio de igualdad y no discriminación. Díaz (2016), p. 195.

${ }^{53}$ Bordalí (2010), p. 92. Por ejemplo, el derecho a la igual protección en el ejercicio de los derechos, el derecho a la defensa jurídica, el derecho a la debida intervención del letrado y a la asistencia jurídica gratuita. El autor también plantea que también forman parte del derecho al debido proceso en la Constitución chilena los derechos procesales reconocidos en tratados internacionales sobre derechos humanos ratificados por Chile y que se encuentren vigentes.

54 Tribunal Constitucional, Rol № 1557-09, de 14 de abril de 2011, considerando 25‥ En otro fallo, el Tribunal Constitucional ha enumerado las garantías que debe contemplar el racional y justo procedimiento, las cuales son: la publicidad de los actos jurisdiccionales, el derecho a la acción, el oportuno conocimiento de ella por la parte contraria, el emplazamiento, la adecuada defensa y asesoría con abogados, la producción libre de pruebas conforme a la ley, el examen y objeción de la evidencia rendida, la bilateralidad de la audiencia, y la facultad de interponer recursos para revisar sentencias dictadas por tribunales inferiores. Tribunal Constitucional, Rol № 1718-10, de 14 de junio de 2011, considerando 7ㅇ․
} 
legalmente tramitado. Corresponderá al legislador establecer siempre las garantías de un procedimiento y una investigación racionales y justos". Dicha disposición ha permitido a la doctrina y a la jurisprudencia extender la aplicación de las garantías del debido proceso a la actividad de la Administración del Estado, aunque tradicionalmente estuvieran concebidas para los procesos judiciales ${ }^{55}$. Con independencia de las causas de la extensión de las garantías del debido proceso a la actividad administrativa, ello ha supuesto que las personas migrantes sean protegidas frente a decisiones arbitrarias de la autoridad migratoria como de los tribunales. Por lo tanto, las exigencias de razonabilidad propias del debido proceso son aplicables tanto a los proceso contencioso-administrativo, que se desarrollan ante los tribunales de justicia, como a los procedimientos administrativos (a través del llamado "debido proceso sustantivo") ${ }^{56}$.

En el derecho chileno, los tribunales de justicia conocen de las impugnaciones a actos administrativos desfavorables a los migrantes (como el caso de los decretos de expulsión), y desarrollan una labor fundamental conociendo de acciones de habeas corpus interpuestas por migrantes expulsados, o cuyo ingreso al país ha sido denegado. La importancia que reviste la exigencia del derecho a un debido proceso para las personas migrantes se plantea especialmente a propósito la expulsión del país, medida más gravosa adoptada en contra de un extranjero.

La regulación del Decreto Ley № 1.094 en esta materia, ha sido objeto de profundos cuestionamientos por parte de la doctrina y la jurisprudencia, a propósito de la configuración tanto del procedimiento administrativo que culmina con el decreto de expulsión, como del mecanismo de impugnación judicial del mismo ${ }^{57}$. En efecto, no contempla una notificación del inicio del procedimiento, sino que el extranjero toma conocimiento de este solo al ser notificado del decreto de expulsión y, en ocasiones, privado de su libertad. En consecuencia, el procedimiento no contempla ni la audiencia del afectado o su representante previo a la dictación de la medida lo que supone una afectación al derecho de defensa ${ }^{58}$. Así lo han señalado también los tribunales de justicia, al advertir que tal como se tramita el procedimiento administrativo de expulsión no se cumple con las exigencias que la propia Ley de Bases de Procedimiento Administrativo contempla. Por ejemplo, se ha resuelto a este respecto que:

\footnotetext{
55 García y Contreras (2013), p. 242.

56 El control migratorio está adscrito a aquellas potestades administrativas llamadas "de policía", de ordenación o limitadoras de derechos. Esto, al suponer la limitación de la libertad de desplazamiento y residencia de los no nacionales, invocando razones de interés general y pretendiendo conservar del orden público. En este sentido, la sentencia del Tribunal Constitucional, Rol № 22732012-INA, de 4 de julio de 2013, considerando 6ㅇ․

${ }^{57}$ Domínguez (2016), p. 197; Bassa y Torres (2016), p. 117.

${ }^{58}$ Bassa y Torres (2016), p. 117.
} 
(...) en el procedimiento a través del cual se resolvió la expulsión del amparado no se respetaron los principios mencionados precedentemente, pues no basta poner en conocimiento del afectado los recursos que puede deducir contra la decisión, sino resulta necesario que previamente se lleve a cabo un proceso en que el extranjero pueda ser oído por una autoridad que actúa con imparcialidad y que exterioriza los razonamientos que motivan el acto administrativo terminal ${ }^{59}$.

Respecto a la posibilidad de ejercer el derecho al recurso en la configuración del sistema de expulsiones, se ha señalado que la ley deniega tanto de iure como de facto, este derecho para las personas migrantes deportadas ${ }^{60}$. Se deniega de iure, toda vez que el mecanismo dispuesto por la ley (el recurso especial de reclamación ante la Corte Suprema) está limitado exclusivamente respecto a aquellas expulsiones realizadas a través de un decreto supremo. Esto, siendo que también puede decretarse la expulsión a través de resolución del Intendente Regional, las que quedarían excluidas injustificadamente ${ }^{61}$.

A su vez, la restringidísima configuración de este recurso de reclamación priva de facto el derecho al recurso. Esto es así, toda vez que debe interponerse exclusivamente ante la Corte Suprema y dentro del plazo de 24 horas desde notificado el decreto de expulsión. Además, solo puede interponerse por el afectado y su familia, siendo que el primero se encuentra privado de libertad desde la notificación del decreto de expulsión, y en muchos casos su familia fuera del país. Esto ha sido también advertido por el Tribunal Constitucional, que ha sostenido que:

Si bien la legislación de extranjería contempla un recurso contra la orden de expulsión o de "abandono voluntario" ante la Corte Suprema (...) se da dentro de un plazo, y en un contexto que resulta prácticamente imposible de ejercer, máxime si una persona jamás ha conocido, litigado, alegado derechos y, previsiblemente incluso, no conozca el idioma que lo permita. Todas estas son vulneraciones al debido proceso y que afectan los derechos directamente establecidos para todos en el artículo 19, numeral 3ํㅡ, de la Constitución ${ }^{62}$.

En los hechos, la impracticable configuración del recurso de reclamación ha exigido la utilización de mecanismos alternativos para la tutela de los derechos de los extranjeros expulsados. El arbitrio procesal por excelencia ha sido el habeas corpus, como acción de tutela jurisdiccional de la libertad personal y la seguridad individual. Este se ha constituido hoy por hoy, y con la venia de la Corte Suprema, en el principal instrumento de impugnación de expulsiones. Al igual que en otros países, la litigación migratoria ha sido un importante

\footnotetext{
${ }^{59}$ Corte Suprema, Rol № 36580-2015, de 17 de diciembre de 2015, considerando 3ํ. En el mismo sentido, se ha señalado que: "no se aplicó el principio de contradictoriedad, pues no se permitió al afectado aducir alegaciones y aportar documentos u otros elementos de juicio; no se respetaron los principios de transparencia y de publicidad, de manera de permitir y promover el conocimiento, contenidos y fundamentos de las decisiones que se adoptaron en contra del amparado; asimismo (...) no se puso en conocimiento del extranjero que se tramitaba en su contra dicha orden de expulsión, ni tuvo oportunidad de formular descargos ni de rendir pruebas". Corte de Apelaciones de Santiago, Rol № 2083-2015, de 4 de diciembre de 2015, considerando 6ㅇ․

60 Domínguez (2016), pp. 197-198.

${ }^{61}$ Domínguez (2016), p. 200.

62 Tribunal Constitucional, Rol № 2273-2012-INA, de 04 de julio de 2013, voto de minoría de los ministros Vodanovic, Carmona y García, considerando 4ํ․
} 
instrumento para contribuir, con mayor o menor éxito a reducir el impacto de la desmejorada posición en que los extranjeros se enfrentan a la autoridad estatal63.

Existen también otros aspectos del estatuto de expulsiones que pugnan con el derecho al debido proceso. Por ejemplo, la atribución de la autoridad migratoria de decretar "sin más trámite" la expulsión de un extranjero en determinados casos, se ha entendido lesiva del debido proceso, puesto que la imposición de una sanción administrativa debe siempre ser el resultado de un procedimiento idóneo sustanciado por un órgano de la Administración64. También se ha planteado que se dificulta la asesoría jurídica a los afectados por una medida de expulsión65.

\subsection{EL DERECHO A LA LIBRE CIRCULACIÓN Y RESIDENCIA (ARTÍCULO 19 № 7 A)}

El reconocimiento y la protección a la libertad de movimiento está presente en la mayoría de las constituciones liberales. Sin embargo, el protagonismo de las migraciones internacionales en las últimas décadas ha exigido prestarle una especial atención ${ }^{66}$. En efecto, este corresponde al principal derecho involucrado durante el proyecto migratorio de una persona o familia, y en el caso de las personas extranjeras, su ejercicio es objeto de control por parte de la autoridad administrativa.

El artículo 19 no 7 literal a) de la Constitución chilena asegura, en términos amplísimos, la libertad de desplazamiento (también llamada "libertad de locomoción”, “de circulación”, o "de movilización") y de residencia. En efecto, este derecho le está reconocido a todas las personas sin distinción, lo que es un rasgo singular de la Constitución chilena en el contexto comparado, donde suele reservarse a los nacionales ${ }^{67}$. Ya en el año 2003, esta cuestión fue advertida por Aldunate, quien sostuvo lo llamativo de la falta de diferenciación entre nacionales y extranjeros en el reconocimiento de este derecho. La consecuencia de dicha situación sería que todo

\footnotetext{
${ }^{63}$ Salyer (2020), pp. 77-103.

${ }^{64}$ El Tribunal Constitucional ha sostenido que es inconstitucional la imposición de sanciones "de plan o", como la expulsión "sin más trámite". Esta hipótesis está contemplada en la Ley de Extranjería, a propósito de aquellas personas con permiso de turista vencido, o que no hubieren abandonado el país voluntariamente una vez vencido dicho permiso. En este sentido, Tribunal Constitucional, Rol № 747, de 31 de agosto de 2007, considerando 11ㅇ․

${ }^{65}$ Las personas migrantes en situación irregular son, por excelencia, los sujetos afectados por las medidas de expulsión. Como resulta evidente, estas personas no poseen Cédula de Identidad chilena, por lo que ven privados de facto, el ejercicio de su derecho a la asistencia jurídica gratuita frente a las Corporaciones de Asistencia Judicial.

${ }^{66}$ Aja (2012), p. 349.

${ }^{67}$ Por ejemplo, la Constitución española establece que: “Los españoles tienen derecho a elegir libremente su residencia y a circular por el territorio español. Asimismo, tienen derecho a entrar y salir libremente de España en los términos que la ley establez ca. Este derecho no podrá ser limitado por motivos políticos o ideológicos". Constitución Española (1978), artículo 19. El tenor literal de esta disposición no ha sido, sin embargo, obstáculo para que la jurisprudencia del Tribunal Constitucional español haya sido variable. En ocasiones, ha extendido el derecho también a los extranjeros. Aja (2012), pp. 350-351.
} 
extranjero tiene el derecho de entrar al país, sin que la Constitución aporte un punto de apoyo normativo para una distinción que prive a los extranjeros de este derecho ${ }^{68}$.

Como se expuso en su oportunidad, el derecho a la igualdad y no discriminación exige que cualquier privación a un derecho fundamental se funde en una habilitación constitucional expresa, que no existe en la Constitución chilena a propósito de la libertad de desplazamiento y residencia para extranjeros. En consecuencia, todo extranjero tendría prima facie el derecho a ingresar a Chile, existiendo un mandato genérico de regulación legislativa para el ejercicio del derecho, más no para impedirlo o prohibirlo69. Esto supondría una regla general de admisión a extranjeros, y el reconocimiento implícito del derecho a inmigrar (cuyo reconocimiento en el derecho internacional es ampliamente discutido ${ }^{70}$ ). Ello ha sido advertido por el propio Tribunal Constitucional:

Que, finalmente, la Constitución, en materia de titularidad específica del derecho fundamental de libertad de locomoción, no realiza ninguna distinción que valide un tratamiento diverso entre extranjero y nacional. (...) Lo anterior implica que el derecho de emigrar que tiene todo extranjero se correlaciona con su derecho de inmigración en Chile, cuyo, ejercicio, pero no el derecho mismo, puede ser modulado, regulado y limitado 'a condición de que se guarden las normas establecidas en la ley y salvo siempre el perjuicio de terceros' ${ }^{71}$.

Aunque esta interpretación coloca en entredicho la constitucionalidad del establecimiento de prohibiciones de ingreso al país presentes en la mayoría de las legislaciones migratorias del mundo, ello no supone un ejercicio ilimitado del derecho. La Constitución mandata al legislador a regular su ejercicio ${ }^{72}$, pero en principio, medidas que supongan su privación estarían fuera del marco constitucional ${ }^{73}$. Esto resulta complejo, en la medida que el control al ingreso constituye el núcleo mismo de la política de control de flujos migratorios. Sin embargo, se ha sostenido

\footnotetext{
${ }^{68}$ Aldunate (2003), pp. 192-193.

${ }^{69}$ Díaz (2016), pp. 187-188.

${ }^{70}$ Por ejemplo, el Pacto Internacional de Derechos Civiles y Políticos reconoce el derecho a circular libremente por el territorio de un Estado y a escoger libremente su residencia en él, exclusivamente a las personas que se hallen legalmente en el país (artí culo 12.1), y también consagra el derecho a salir libremente de cualquier país, aunque sin el derecho a entrar a otro (artículo 12.2). También la Convención Americana de Derechos Humanos (artículo 22). Sobre la libertad de circulación y residencia en la Convención Americana de Derechos Humanos, ver Uprimny y Sánchez (2020), pp. 645-670. El Comité de Derechos Humanos, en su Observación General № 15, sostuvo que no existe el derecho de la persona extranjera a entrar y permanecer en el territori o de un Estado que no sea el de su nacionalidad, por lo que es legítimo que se condicione su entrada a ciertos requisitos.

${ }^{71}$ Tribunal Constitucional, Rol № 2273-2012-INA, de 4 de julio de 2013, considerando 35‥

${ }^{72}$ El artículo 19 no 7 literal a) reconoce el derecho "a condición de que se guarden las normas establecidas en la ley".

${ }^{73}$ Esta reflexión ha estado ausente en la doctrina constitucional chilena más tradicional, que sin invocar argumentos de texto se ha limitado a sostener que la admisión de los extranjeros "tiene que quedar sometida a la expresión de la libre voluntad de nues tra República, la cual, incluso, puede en ciertos casos, aceptar el asilo". Silva (2008) p. 24. En el mismo sentido, se ha planteado que la situación de los extranjeros es un límite a la libertad personal, en la medida que "aún cuando nuestro ordenamiento reconoce a los extranjeros las mismas facultades que a los chilenos en materia de adquisicion y goce de los derechos civiles, no es menos cierto que, como lo hacen todas las legislaciones del mundo, en materia de su ingreso o permanencia en el territorio nacional, la le gislación contiene ciertas limitaciones a fin de precaverse contra "elementos que puedan resultar indeseables". Vivanco (2007), p. 327.
} 
frente a un escenario similar, que podría identificarse un contenido mínimo de este derecho fundamental en algunos supuestos humanitarios y de no devolución ${ }^{74}$.

En relación a las restricciones a este derecho impuestas por la autoridad migratoria, la Corte Suprema ha sostenido como criterio general que resulta necesario invocar fundamentos razonables, lo que significa considerar los antecedentes del caso y ponderar la necesidad de satisfacer el derecho, considerando los objetivos de la regulación nacional75. Cualquier medida que conculque los derechos de permanencia en cualquier lugar del país, de viajar por él, de cambiar su residencia, de salir y entrar al territorio nacional, y en general, que coarte este derecho solo pueden imponerse en los casos y con las exigencias formales y sustantivas de un justo y racional proceso ${ }^{76}$. Dentro de estas medidas están comprendidas, por ejemplo: la prohibición de ingreso al país ${ }^{77}$, el rechazo de una solicitud de visado ${ }^{78}$, la expulsión del país, o incluso la demora o rechazo injustificado en otorgar pasaporte ${ }^{79}$. De este modo, el mecanismo de tutela jurisdiccional de la libertad ambulatoria, el habeas corpus, ha asumido la posición de mecanismo idóneo para garantizar la facultad de residir y transitar por el territorio nacional de que gozan las personas migrantes ${ }^{80}$.

\section{Reflexiones en torno al tratamiento a la inmigración en una nueva Constitución}

El que la titularidad de todos los derechos consagrados en el catálogo del artículo 19 de la Constitución de 1980 se extienda sin diferenciar entre nacionales y extranjeros, ha constituido la principal garantía para la protección de los derechos de las personas migrantes en Chile. Sin embargo, la realidad ha sido que esto no ha sido suficiente para evitar los efectos perjudiciales de una legislación preconstitucional e irrespetuosa de dichos estándares como el Decreto Ley № 1.094 de 1975. El tratamiento a la inmigración por parte de este marco legal se realizó desde una mirada exclusivamente enfocada en la seguridad nacional y el orden interior. Esto, sumado al

\footnotetext{
${ }^{74}$ Aja (2012), p. 351.

75 Godoy y Didier (2014), pp. 141-142.

${ }^{76}$ Evans de la Cuadra (1999), p. 179.

77 Por ejemplo, al resolverse que "la decisión de impedir el ingreso de la amparada al país, fue ilegal y arbitraria y vulneró la libertad de desplazamiento de la amparada, puesto que no existe justificación alguna que fundamente la actuación desplegada por la autoridad recurrida, razones por las cuales el recurso interpuesto será acogido". Corte Suprema, Rol 3563-2013, de 04 de junio de 2013, considerando $2^{\circ}$.

78 Por ejemplo, al resolverse que “(...) la decisión de la autoridad recurrida consistente en negar el otorgamiento de una visa de residencia permanente para ingresar a Chile constituye un acto ilegal y arbitrario que vulnera la garantía del artículo 19 no 7 de la Carta Fundamental”. Corte Suprema, Rol № 11521-2014, de 12 de junio de 2014, considerando 9o․

${ }^{79}$ Esto último, evidentemente, en el caso de los nacionales chilenos en relación con la actividad administrativa del Servicio de Registro Civil e Identificación. Silva (2008), p. 25.

${ }^{80}$ Henríquez (2018).
} 
amplísimo margen de discrecionalidad que se concedió a la autoridad migratoria para el ejercicio de sus atribuciones, propició múltiples arbitrariedades y discriminaciones lesivas de los derechos de las personas migrantes.

Tal como es posible advertir a partir de lo expuesto hasta aquí, ha sido la acción de los tribunales de justicia la que ha permitido dar efectividad a este marco constitucional, oficiando de principal garante de los derechos de los migrantes. Esta acción, aunque significativa y valiosa, no logra constituirse en una protección general y extendida, sino que únicamente restringida a los casos en que se ha hecho valer un mecanismo de tutela jurisdiccional de derechos. En consecuencia, aunque la Constitución de 1980 ha establecido un marco particularmente garantista con los derechos de los extranjeros, este ha sido claramente insuficiente, al no contemplar pautas más explícitas dirigidas a un tratamiento por parte del legislador. De allí que el proceso constituyente en curso resulte una oportunidad única para la configuración de un estatuto constitucional que, preservando los rasgos garantistas del actual texto, avance en dirección hacia un tratamiento estatal de la inmigración compatible con el respeto y garantía de los derechos humanos.

La realidad actual exige que la futura Constitución se haga cargo de este rasgo estructural de la sociedad chilena del s. XXI, cual es su carácter de sociedad receptora de inmigración. Aquello demanda ofrecer respuestas constitucionales adecuadas a los desafíos que esto significa, las que al menos debieran atender a las siguientes consideraciones:

\subsection{TITULARIDAD DE DERECHOS AUSENTE DE DIFERENCIAS BASADAS EN LANACIONALIDAD}

En primer lugar, se hace necesario dar continuidad al tratamiento constitucional que hasta ahora ha existido en materia de derechos de los extranjeros en Chile, y que se ha prolongado a lo largo de nuestra historia constitucional. Como revisamos en su oportunidad, la Constitución de 1980 ha extendido a todas las personas la titularidad de los derechos consagrados en el catálogo iusfundamental, sin distinciones basadas en la nacionalidad. Aquello corresponde a una medida básica para la implementación del principio de universalidad de los derechos humanos, y a un piso mínimo imperativo para el diseño de políticas migratorias que resguarden adecuadamente dichos derechos. El mantenimiento de esta tendencia debe, sin embargo, complementarse con una adecuada consideración de la calidad de grupo desaventajado que padece el colectivo migrante, que bien podría explicitarse junto a la situación de otros colectivos 
que se encuentran en similar situación. Esto, fundamentalmente en materia de regulación del derecho a la igualdad y no discriminación.

En el actual tratamiento constitucional ha destacado también la incorporación de los extranjeros avecindados en el país a la vida cívica, a través del reconocimiento de su derecho a sufragio en todas las elecciones periódicas y plebiscitos. Este es otro rasgo de la Constitución de 1980 cuya continuidad o progresión resulta necesaria para hacer frente al desafío de la integración. Aquí, el proceso constituyente se presenta como una oportunidad excepcional para replantear el papel que ha jugado la ciudadanía y los rasgos que la han caracterizado, que generalmente han significado excluir a las personas migrantes del ejercicio de derechos políticos en sus países de acogida.

Resultaría, por ejemplo, interesante discutir en torno a la posibilidad de extender la ciudadanía no solo a los nacionales, sino que también a aquellos extranjeros avecindados en Chile durante un periodo que ofrezca garantías de arraigo. Esto permitiría a aquellos extranjeros que, por distintos motivos, no han optado a la nacionalidad chilena, elegir y ser elegidos para el ejercicio de algunos cargos de elección popular. La participación política de los extranjeros avecindados (en todos los niveles, aunque con especial importancia en el nivel local) representa una necesidad democrática considerando que existen regiones donde la población migrante alcanza porcentajes significativos del total de habitantes.

\subsection{POLÍTICAS DE CONTROL MIGRATORIO CENTRADAS EN LAS PERSONAS}

En segundo lugar, resulta del todo conveniente incorporar directivas constitucionales que conduzcan la actividad estatal hacia la adopción de políticas migratorias que coloquen en el centro a las personas, desechando un enfoque netamente "securitizado", potencialmente lesivo del ejercicio de derechos fundamentales. En muchos Estados, el diseño de las políticas de control a la inmigración se ancla en la perspectiva de la seguridad nacional y el orden público, asociándola casi exclusivamente a fenómenos como el terrorismo, el narcotráfico o la delincuencia organizada81. Por el contrario, sería conveniente incorporar pautas constitucionales que vinculen al Estado chileno hacia el diseño y la implementación de políticas de control migratorio que prioricen el respeto a los derechos humanos de las personas

81 Velasco (2016), p. 41. 
migrantes, subordinando a estos sus competencias en materia de admisión, visado y expulsión de extranjeros.

Un compromiso constitucional en este sentido se hace necesario cuando los vaivenes políticos han llevado al frente del gobierno de múltiples Estados a coaliciones que han utilizado la presencia de inmigrantes como "chivo expiatorio" para la adopción de políticas cortoplacistas, partidistas e instrumentales, en miras de conseguir ventajas electorales. Además, el "despotismo legislativo" puede llegar a ser también una amenaza para colectivos especialmente vulnerables, como los migrantes ${ }^{82}$. Tal como destaca Javier de Lucas, la gestión de la inmigración debiera, en cambio, "ser parte del proyecto básico de convivencia y, por tanto, ser objeto de un verdadero pacto de Estado"83.

\subsection{INTEGRACIÓN E INTERCULTURALIDAD}

En tercer lugar, se hace necesario, además, incorporar directivas constitucionales que conduzcan la actividad estatal hacia la adopción de políticas públicas que favorezcan la integración de las comunidades migrantes en el país. Esto, considerando que el tratamiento estatal al fenómeno migratorio no puede centrarse exclusivamente en la dimensión del control al ingreso y la permanencia de extranjeros en el país. En esta materia, la Constitución de 1980 impone al Estado el deber de "promover la integración armónica de todos los sectores de la Nación" y de "asegurar el derecho de las personas a participar con igualdad de oportunidades en la vida nacional" (artículo 1 inciso $5^{\mathrm{o}}$ ) $^{84}$. Sin embargo, este imperativo constitucional no se ha logrado traducir en la adopción de políticas de integración en relación a la comunidad migrante.

La "integración" juega un papel sumamente relevante en el diseño de las políticas migratorias a nivel comparado. Aunque esta expresión ha recibido interpretaciones muy distintas, puede decirse que su elemento central dice relación con favorecer la convivencia entre grupos y culturas diversas ${ }^{85}$. Aunque suele confundirse con la "inserción social" de los migrantes en la comunidad receptora, lo que caracteriza las políticas de integración es la incorporación de los inmigrantes a una sociedad receptora en igualdad de oportunidades con los nacionales ${ }^{86}$, a través de garantías de acceso igualitario a los derechos universales ${ }^{87}$. La integración es uno de

\footnotetext{
82 Sobre este punto, Mayorga (2019), pp. 131-133.

${ }^{83}$ De Lucas (2016), p. 103.

${ }^{84}$ Sobre este punto, Molina (2019), pp. 244-247.

${ }^{85}$ Aja (2012), p. 441.

86 Torres (2002), p. 51.

${ }^{87}$ Lages (2019), pp. 39-40.
} 
los principales desafíos que los Estados receptores de flujos de migración deben enfrentar. Lo hacen a través de múltiples frentes, entre muchos otros, a través del combate al racismo y la xenofobia. Además, para que la integración no resulte una mera y simple asimilación, ha de ser bilateral, no solo adoptando medidas en relación a los inmigrantes, sino que también en relación a la sensibilización de la ciudadanía88.

\subsection{RESERVA LEGAL EN MATERIAS DE INMIGRACIÓN Y EXTRANJERÍA}

Por último, desde lo orgánico, el diseño de una distribución de competencias estatales que resguarde los derechos fundamentales de los migrantes se traduce en la exigencia de la reserva de ley para materias relativas a inmigración y extranjería, garantizando así una regulación que sea producto de una deliberación pública y democrática. De esta manera se evitarían cambios bruscos en la definición de la política migratoria por parte de la Administración, autorizando el ejercicio de la potestad reglamentaria en materias expresamente definidas por el legislador. Como mencionamos en un apartado previo, en el derecho constitucional comparado es frecuente la existencia de disposiciones en este sentido, considerando que las políticas migratorias son una materia especialmente sensible para el respeto y garantía de los derechos humanos. Sin embargo, en el Derecho Constitucional chileno, la ausencia de una disposición expresa en este sentido, ha abierto un excesivo espacio a la potestad reglamentaria, que ha resultado lesivo de los derechos de las personas migrantes. En esto también ha incidido de manera gravitante el hecho que la legislación de extranjería haya tenido una data previa a la vigencia de la propia Constitución de 1980. En efecto, el Decreto Ley № 1.094 de 1975, entregó amplias facultades reglamentarias a la Administración, y además concedió una amplísima discrecionalidad a la autoridad migratoria a la hora de resolver acerca del ingreso y la permanencia de extranjeros en Chile ${ }^{89}$. Desafortunadamente el proyecto de nueva Ley de Migración y Extranjería, que actualmente se encuentra en la etapa final de su tramitación, da continuidad a este aspecto problemático ${ }^{90}$.

\footnotetext{
${ }^{88}$ De Lucas (2016), p. 105.

${ }^{89}$ Bassa y Torres (2016), p. 109-111.

${ }^{90}$ En el proyecto de ley existen normas que conceden espacios de discrecionalidad a la autoridad migratoria administrativa sin exigir el cumplimiento de un estándar de razonabilidad mínima. Es, por ejemplo, el caso del artículo 27 inc. 2, que habilita a la autoridad migratoria administrativa a exigir a los nacionales de determinados países un visado consular "por motivos calificados de interés nacional" y "de bajo cumplimiento de las normas migratorias por parte de los nacionales de un país en particular".
} 


\section{Conclusiones}

Pese a que aún sea posible identificar discursos en los que el diseño y la implementación de políticas migratorias por parte de los Estados es una competencia discrecional que, al ser un atributo inherente la soberanía territorial, podría ejercerse al margen de prácticamente cualquier consideración distinta al interés puramente estatal; la realidad es que, tal como ha señalado el Tribunal Constitucional chileno, el control migratorio es una competencia que “(...) está sujeta a límites materiales que provienen desde la Constitución, el Derecho Internacional, y especialmente, desde el Derecho Internacional de los Derechos Humanos"91.

Respecto al marco constitucional de la inmigración en Chile, es efectivo que ninguna disposición de la Constitución de 1980 se pronuncia explícitamente sobre el fenómeno de las migraciones. Sin embargo, ello no ha sido obstáculo para que, a partir de la doctrina y jurisprudencia constitucional, sea posible indicar que se trata de un marco constitucional particularmente garantista o amigable en lo que dice relación con los derechos de los extranjeros en Chile.

En la práctica ello se ha traducido en el rediseño, por vía jurisprudencial, del alcance con que se habían ejercido potestades como la admisión, el visado o la expulsión del país. Este fenómeno no se ha manifestado exclusivamente en el derecho chileno, puesto que otros ordenamientos jurídicos donde tampoco existen pautas constitucionales para el control de la inmigración, también han aplicado disposiciones constitucionales generales para dejar sin efecto actos de la autoridad migratoria que lesionan principios básicos del orden constitucional, o derechos fundamentales de las personas migrantes y sus familias.

En el caso de la Constitución de 1980, ha sido fundamentalmente su sistema de derechos constitucionales el que ha permitido hacer referencia a un marco particularmente garantista o amigable en materia de derechos de los migrantes. Aunque los tratados internacionales de derechos humanos ratificados por Chile y vigentes forman parte del "bloque de constitucionalidad" por la vía del artículo 5ํ inciso segundo, la protección constitucional actual supera en intensidad a la protección internacional, producto de la amplitud con que se han regulado materias como la titularidad de los derechos constitucionales o la regulación del derecho a la libertad de circulación y residencia. En efecto, no puede decirse que en el orden internacional las diferencias de titularidad de derechos entre nacionales y extranjeros sean

91 Tribunal Constitucional, Rol № 2273-12, de 4 de julio de 2013, considerando 7ํ․ 
excepcionales, como tampoco puede decirse que el derecho a la libre circulación se consagre con el alcance que lo ha hecho la actual Constitución chilena. Esto último ha llevado incluso a plantear la existencia de un derecho a inmigrar en la Constitución chilena, cuestión que no sería fácil de plantear en el marco del Derecho Internacional.

En el contexto comparado, existen textos constitucionales que, con pronunciamientos explícitos, incorporan pautas y directivas para el tratamiento estatal de la inmigración. En algunos casos estos pronunciamientos tienen un carácter más restrictivo, y en otros, una inclinación de mayor valoración o predisposición frente al fenómeno de la inmigración. La experiencia comparada debe considerarse, teniendo presente la actual discusión sobre una nueva Constitución. El proceso constituyente nos ofrece una oportunidad invaluable para discutir y adoptar un nuevo pacto con la movilidad humana, cuyos términos no oscilen según sean mayores o menores las ventajas posibles de alcanzar en cada ciclo electoral. Cuando cerca de un $8 \%$ de la población nacional está compuesto por personas en contexto de movilidad internacional, debe discutirse con seriedad la necesidad de incluir en la Constitución referencias que, desde lo sustantivo y desde lo orgánico, contribuyan a garantizar que la relación del Estado con la inmigración no dependa de decisiones "cortoplacistas, partidistas o instrumentales ${ }^{92}$ ".

Este "nuevo trato" constitucional con la movilidad humana no debe limitarse exclusivamente al fenómeno del llamado desplazamiento "voluntario". El desplazamiento forzado es igualmente un asunto de relevancia, considerando la cada vez menos perceptible frontera que separa a quienes se desplazan a un país distinto al de su nacionalidad de manera voluntaria y a quienes lo hacen huyendo de la persecución, la pobreza, los conflictos internos, las violaciones a los derechos humanos o la crisis climática.

En cualquier caso, y tal como ha sido expuesto aquí, un nuevo estatuto constitucional para la inmigración debiera tomar los elementos centrales que han permitido considerar particularmente garantista a la Constitución de 1980 en esta materia, y darles continuidad. Simultáneamente, es una necesidad incorporar pautas que guíen la acción estatal hacia la adopción de políticas migratorias respetuosas de los derechos humanos y que promuevan la integración de las comunidades migrantes en Chile. Estas serían apenas un par de medidas que contribuirían a la formación de un pacto social que ofrezca garantías de una convivencia pacífica y democrática con la migración. Cualquier otro cambio dirigido a la adopción de un sistema

92 De Lucas (2016), p. 103. 
económico y social que introduzca mayor justicia social, y en que el Estado asuma verdadero un rol de garante en el ejercicio de derechos, beneficiará también a las personas migrantes.

\section{Bibliografía citada}

Aja, Eliseo (2012): Inmigración y democracia (Madrid, Alianza Editorial).

Aldunate Lizana, Eduardo (2003): "La titularidad de los derechos fundamentales", en Estudios Constitucionales (Año 1, № 1), pp. 187-201.

(2008): Derechos Fundamentales (Santiago, Legal Publishing).

Alessandri, Arturo; Somarriva, Manuel y Vodanovic, Antonio (2007): Tratado de Derecho Civil: Partes Preliminar y General, 8º edición, (Santiago, Editorial Jurídica de Chile), Tomo I.

Arelattaz, Fernando (2018): “Admisión y expulsión de extranjeros en el Derecho argentino”, en Estudios Constitucionales (Año 16, № 1), pp. 281-326.

Bassa Mercado, Jaime y Torres Villarrubia, Fernanda (2016): “Desafíos para el ordenamiento jurídico chileno ante el crecimiento sostenido de los flujos migratorios", en Estudios Constitucionales (Año 13, № 2), pp. 103-124.

Bordalí Salamanca, Andrés (2010): La independencia judicial en el derecho chileno (Santiago, Legal Publishing).

Cea Egaña, José Luis (2012): Derecho Constitucional Chileno, Tomo II: Derechos, Deberes y Garantías, 3ํe edición, (Santiago, Ediciones Universidad Católica de Chile).

Contreras, Pablo (2017): “Titularidad de los derechos fundamentales”, en Contreras, Pablo y Salgado, Constanza (editores), Manual sobre derechos fundamentales: Teoría general (Santiago, LOM), pp. 119-160.

De Lucas, Javier (2011): “Inmigrantes: Del Estado de excepción al Estado de derecho”, en Oñati Socio-Legal Series (Vol. 1, № 3), 14 páginas.

(2016): "Refugiados e inmigrantes: Por un cambio en las políticas migratorias y de asilo", en Pasajes (№ 50), pp. 92-113. 
Díaz García, Iván (2013): “Ley chilena contra la discriminación. Una evaluación desde los derechos internacional y constitucional”, en Revista Chilena de Derecho (Vol. 40, № 2), pp. 635-668.

Díaz Tolosa, Regina (2016): "Ingreso y permanencia de las personas migrantes en Chile: compatibilidad de la normativa chilena con los estándares internacionales", en Estudios Constitucionales (Año 14, № 1), pp. 179-220.

Domínguez Valverde, Cecilia (2016): “Derecho Chileno Migratorio a la luz del Derecho Migratorio Internacional: ¿Ceden los Derechos Humanos mínimos de los extranjeros ante las prerrogativas soberanas de control migratorio?, en Revista Chilena de Derecho (Vol. 43, № 1), pp. 189-217.

Evans de la Cuadra, Enrique (1999): Los derechos constitucionales, $2^{\text {o }}$ edición, Tomo II (Santiago, Editorial Jurídica de Chile).

Favoreu, Louis Joseph (2001): “La constitucionalización del Derecho”, en Revista de Derecho (Valdivia) (Vol. 12), pp. 31-43.

Fermandois Vöhringer, Arturo (2006): Derecho Constitucional Económico, Tomo I (Santiago, Ediciones Universidad Católica de Chile).

Fiss, Owen (1999): “Grupos y la Cláusula de Igual Protección”, en Gargarella, Roberto (editor), Derecho y Grupos Desaventajados (Barcelona, Gedisa), pp. 137-167.

García Pino, Gonzalo y Contreras Vásquez, Pablo (2013): "El derecho a la tutela judicial y al debido proceso en la jurisprudencia del Tribunal Constitucional chileno", en Estudios Constitucionales (Año 11, № 2), pp. 229-282.

Godoy Araya, Rodrigo y Didier Von der Hundt, Marcel (2014): “Comentarios de jurisprudencia de la Corte Suprema y el Tribunal Constitucional sobre derechos humanos de las personas migrantes durante el año 2013”, en Anuario de Derechos Humanos (№ 10), pp. 139-150.

Henríquez Viñas, Miriam (2018): “El habeas corpus contra las expulsiones ilegales y arbitrarias de migrantes", en Revista de Derecho Aplicado LLM UC (№ 1). 
Instituto Nacional de Estadísticas y Departamento de Extranjería y Migración (2020): “Informe Estimación de Extranjeros Residentes en Chile al 31 de diciembre de 2019”. [Disponible en: https://bit.ly/2YzxqOp]. [Fecha de consulta 27 de noviembre 2020].

Lages de Oliveira, Rita (2019): “Migración internacional y Derecho: una reflexión en clave de derechos humanos", en Anales de la Universidad de Chile (№ 16), pp. 27-45.

Lara Escalona, María Daniela (2014): “Evolución de la legislación migratoria en Chile: Claves para una lectura (1824-2013)", en Revista de Historia del Derecho (№ 47), pp. 59-104.

Mayorga Mc Donald, Ramón (2019): “Minorías, grupos desaventajados y justicia constitucional: el caso de los migrantes", en Charney, John (editor), Derecho y Migración. Actas de las XLVII Jornadas Chilenas de Derecho Público (Valparaíso, Ediciones Universitarias de Valparaíso), pp. 127-146.

Molina Conzué, Diego (2019): “Principios de Derecho Migratorio chileno desde una óptica constitucional", en Charney, John (editor), Derecho y Migración. Actas de las XLVII Jornadas Chilenas de Derecho Público (Valparaíso, Ediciones Universitarias de Valparaíso), pp. 235251.

Montilla, José Antonio (1999): “La crítica a la protección de las minorías en Alemania”, en Revista de Estudios Políticos (Nueva Época) (№ 106), pp. 111-136.

Salyer, J. C. (2020): Court of Injustice. Law without recognition in U.S. Immigration (Stanford, Stanford University Press)

Silva Bascuñán, Alejandro (2008): Tratado de Derecho Constitucional, 2º edición, Tomo XII (Santiago, Editorial Jurídica de Chile).

Stefoni, Carolina y Brito, Sebastián (2019): “Chile: un destino más en el mapa migratorio intrarregional”, en Rojas, Nicolás y Vicuña, José Tomás (editores), Migración en Chile. Evidencia y mitos de una nueva realidad (Santiago, LOM), pp. 23-47.

Tapia Rodríguez, Mauricio (2005): Código Civil 1855-2005: evolución y perspectivas (Santiago, Editorial Jurídica de Chile). 
Tijoux, María Emilia (2018): “La potencia del racismo cotidiano: sufrir por el cuerpo”, en Tapia, Marcela y Liberona, Nanette (editoras), El afán de cruzar las fronteras. Enfoques transdisciplinarios sobre migraciones y movilidad en Sudamérica y Chile (Santiago, RIL Editores), pp. 47-60.

Torres, Francisco (2002): “La integración de los inmigrantes y algunos de los desafíos que nos plantea”, en De Lucas, Javier y Torres, Francisco (editores), Inmigrantes: ¿cómo los tenemos? Algunos desafíos y (malas) prácticas (Madrid, Talasa), pp. 49-73.

Uprimny, Rodrigo y Sánchez, Luz María (2020): “Artículo 22. Derecho de circulación y residencia", en Steiner, Christian y Fuchs, Marie-Christine (editores), Convención Americana sobre Derechos Humanos. Comentario (Ciudad de México, Tirant lo Blanch), pp. 645-670.

Velasco, Juan Carlos (2016): El azar de las fronteras. Políticas migratorias, ciudadanía y justicia (Ciudad de México, Fondo de Cultura Económica).

Vivanco, Ángela (2007): Curso de Derecho Constitucional, 2oe edición, Tomo II (Santiago, Ediciones Universidad Católica de Chile)

Zúñiga Urbina, Francisco (1998): “El estatus constitucional de extranjeros”, en Revista de Derecho (Concepción) (Vol. LXVI, № 203), pp. 301-330.

\section{Normas jurídicas citadas}

Código Civil, texto refundido y sistematizado publicado con fecha 30 de mayo de 2000.

Constitución de la Nación Argentina, promulgada con fecha 03 de enero de 1995.

Constitución de la República Oriental del Uruguay, publicada con fecha 02 de febrero de 1967.

Constitución Española, publicada en el Boletín Oficial del Estado con fecha 29 de diciembre de 1978.

Constitución Política de la República de Chile de 1980, texto refundido y sistematizado publicado con fecha 22 de septiembre de 2005.

Constitución Política de la República de Honduras, publicada con fecha 11 de enero de 1982. 
Constitución Política de la República de Panamá, promulgada el 11 de octubre de 1972.

Constitución de la República de Ecuador, promulgada el 20 de octubre de 2008.

Constitución de la República de El Salvador, publicada con fecha 20 de diciembre de 1983.

Constitución de la República Federativa de Brasil, promulgada con fecha 05 de octubre de 1988.

Convención Americana de Derechos Humanos, publicada en Chile con fecha 05 de enero de 1991.

Decreto Ley № 1.094 que establece normas sobre extranjeros en Chile, publicado con fecha 19 de julio de 1975.

Decreto Supremo № 597, que establece Reglamento de Extranjería, publicado con fecha 24 de noviembre de 1984.

Ley Fundamental de la República Federal de Alemania, promulgada con fecha 23 de mayo de 1949.

Pacto Internacional de Derechos Civiles y Políticos, publicado en Chile con fecha 27 de mayo de 1989.

\section{Jurisprudencia citada}

Consejo de Estado francés: Ministre de Intérieur contre Dame Montcho, 11 de julio de 1980.

Corte de Apelaciones de Santiago: Ciudadana de nacionalidad coreana contra Piscina Mund (recurso de protección), Rol № 486-93 de 07 de abril de 1993.

Tribunal Constitucional de Chile: María Isabel Reyes Kokisch (requerimiento de inaplicabilidad por inconstitucionalidad), Rol № 747 de 31 de agosto de 2007.

Tribunal Constitucional de Chile: Sociedad Ocean Front S.A. (requerimiento de inaplicabilidad por inconstitucionalidad), Rol № 811-2007 de 31 de enero de 2008. 
Tribunal Constitucional de Chile: ISAPRE Cruz Blanca S.A. (requerimiento de inaplicabilidad por inconstitucionalidad), Rol № 1557-09 de 14 de abril de 2011.

Tribunal Constitucional de Chile: Adolfo Hernán Fuenzalida Cerpa (requerimiento de inaplicabilidad por inconstitucionalidad), Rol № 1718-10 de 14 de junio de 2011.

Tribunal Constitucional de Chile: Control de constitucionalidad del proyecto de ley que modifica la ley $N^{\circ} 18.216$ que establece medidas alternativas a las penas privativas o restrictivas de libertad, Rol № 2230-2012-CPR de 05 de junio de 2012.

Corte Suprema de Chile: Grimalda Velásquez Ccanccahua contra Jefe de Prefectura Policía Internacional Aeropuerto de Santiago (recurso de amparo), Rol 3563-2013 de 04 de junio de 2013.

Tribunal Constitucional de Chile: Daniel Alerte (requerimiento de inaplicabilidad por inconstitucionalidad), Rol № 2273-2012-INA de 04 de julio de 2013.

Corte Suprema de Chile: Soufien Lahouel contra Ministerio de Relaciones Exteriores (recurso de amparo), Rol № 11521-2014 de 12 de junio de 2014.

Corte de Apelaciones de Santiago: José Luis Quijandria Pino contra Intendencia Regional de Tarapacá (recurso de amparo), Rol № 2083-2015 de 04 de diciembre de 2015.

Corte Suprema de Chile: José Luis Quijandria Pino contra Intendencia Regional de Tarapacá (recurso de amparo), Rol № 36580-2015 de 17 de diciembre de 2015.

Tribunal Constitucional de Chile: Requerimiento de inconstitucionalidad presentado por un grupo de H. Diputados, respecto del Decreto Supremo No 776 que establece visto consular de turismo a nacionales de Haití, Rol № 4757-18-CDS de 19 de julio de 2018. 